\title{
Validation and Reliability of PedsQL in Healthy Malaysian Pediatric Population
}

\author{
Shanthi Varatharajan ${ }^{1} \&$ Won-Sun Chen ${ }^{2}$ \\ ${ }^{1}$ Ministry of Health, Malaysia \\ ${ }^{2}$ Info Analytic, Malaysia \\ Correspondence: Won-Sun Chen, Info Analytic, Suite 129, MBE Kota Damansara, Lot G-63 \& G-64, Jalan PJU \\ 5/1, 47810 Petaling Jaya, Selangor, Malaysia. E-mail: chenwonsun@gmail.com
}

Received: October 26, 2012 Accepted: November 10, 2012 Available online: February 4, 2013

doi:10.11114/ijsss.v1i1.61 URL: http://dx.doi.org/10.11114/ijsss.v1i1.61

\begin{abstract}
This study aimed at examining the validity and reliability of the translated PedsQL instruments in healthy Malaysian pediatric population. Study population consisted of children aged 5-7 and $8-12$ years as well as adolescent aged 13- 18 years recruited from the continently selected primary and secondary schools located in Klang valley area. All participants were requested to obtain parental consent. The participants must possess the ability to read and understand the questionnaire independently in any one of the languages, namely English, Malay, Tamil and Mandarin. Both forward and backward translation process was adopted in translating the instruments. A harmonization meeting involving all the translators and researchers was then held to review, reconcile and harmonize the translated instruments. Cronbach's alpha was used to demonstrate the internal reliability of the instruments with a 2-weeks period. The predictive strength of the parent proxy report on the child self report was studied using the predictive validity. The Cronbach's alpha values for child self report in all versions of PedsQL were found to be at least 0.70 while the values were reported to be at least 0.80 for the parent proxy report. Moderate correlation between the child self report and parent proxy report was observed for children aged 5-7 and 8-12 years, while the correlation was moderate to high for children aged 13-18 years. The findings in this study demonstrated the Malay, Mandarin and Tamil PedsQL possessed acceptable internal reliability and predictive validity.
\end{abstract}

Keywords: health related quality of life, validity, reliability, pediatric

\section{Introduction}

Psychosocial health has been termed as a "new hidden morbidity" in pediatric health care, to reflect the identification of psychosocial problems in routine pediatric practice (Varni, Seid, Knight, Uzark, \& Szer, 2002). Frequent hospitalizations, intrusive medical procedures, and uncertainty of survival can negatively impact the childhood development and adjustment (Spieth, \& Harris, 1996). In recent years, significant acknowledgement and attention have focused on the Pediatric Health Related Quality of Life (HRQOL). A number of generic and disease specific HRQOL instruments have been established specifically for children and adolescents (Eiser, \& Morse, 2001; Koot, \& Wallander, 1999; Varni, Limbers, \& Burwinkle, 2007).

The Pediatric Quality of Life Inventory ${ }^{\mathrm{TM}}$ (PedsQL ${ }^{\mathrm{TM}}$ ) 4.0 Generic Score Scale was first developed in the United States of America and was specifically designed to integrate the merits of generics and disease-specific instruments (Varni, Seid, \& Rode, 1999). The 23-item PedsQL comprises physical functioning (8 items), emotional functioning (5 items), social functioning (5 items), and school functioning (5 items) (Varni, Burwinkle, Seid, \& Skarr, 2003). Past study has demonstrated satisfactory psychometric properties in both the child self-report and the parent proxy-reports (Varni, Seid, \& Rode, 1999). This instrument is applicable to children as young as 5 years old and it is an ideal HRQOL instrument to test the lower age limits achievable for pediatric patient self-reported HRQOL (Varni, Seid, \& Rode, 1999). The PedsQL instrument which has been widely translated and validated in multi languages, include a child self-report for ages 5-18 and a parent proxy-report for child ages 2-18 (Varni, Limbers, \& Burwinkle, 2007).

The PedsQL measurement model emphasizes the child's perceptions of the quality of life. Although child self-report is considered as the standard for measuring perceived HRQOL, it is equally important to measure the 
parent's perception of their child's HRQOL that influences health care utilization (Varni, \& Setoguchi, 1992; Varni, Seid, \& Kurtin, 2001). The use of proxy-report to estimate HRQOL may only be necessary when the child is either unable or unwilling to complete the HRQOL measure. However, one should bare in mind that the proxy-reports should be treated only as an approximation; it may be insufficiently accurate (Blazeby et al., 1995).

Malaysia is a country located in the Southeast Asia with a population of 29.44 million and a reported Gross Domestic Product of 4.7\% in the first quarter of 2012 (Department of Statistics Malaysia, n.d.). The major ethnic groups in Malaysia are Malay, Chinese and Indian. Although Malay is the national language in Malaysia, majority of the population are fluent in at least two other languages mainly English, Mandarin and Tamil.

The objectives of this study was to determine the validity and reliability of the translated PedsQL instrument in Malay, Mandarin and Tamil languages among the healthy Malaysian population in the age range of 5 to 18 years old.

\section{Method}

\subsection{Translation Process}

Two independent professional bilingual translators were hired to translate the original English version of PedsQL into Malay, Mandarin and Tamil. The process consisted of forward and backward translations which were able to examine the internal consistency thus determining the test - retest reliability of the translated PedsQL. A harmonization meeting involving all the translators and researchers was then held to review, reconcile and harmonize the translated instruments.

\subsection{Sample Size Justification}

With an assumption of two replicates per participant, the expected inter-rater reliability of 0.8 or higher $\left(\mathrm{H}_{1}\right.$ : $\rho_{1}=0.8$ ), the acceptable reliability of at least $0.7\left(\mathrm{H}_{0}: \rho_{0}=0.7\right), \alpha=5 \%$ and $\beta=20 \%$ (corresponds to $80 \%$ power), then, the estimated sample size was 118 participants (Walter, Eliasziw, \& Donner, 1998). A total number of 150 participants were required for each language with a further assumption of $27 \%$ non-response rate. The total sample size was approximated to be 600 covering four languages. Since PedsQL is applicable to children in the age range of 5-7 and 8-12 as well as adolescent in the age range of 13-18, therefore, sample size of approximately 1800 was required for the study.

\subsection{Inclusion Criteria}

All participants must be in the age range of 5-18 years. They must possess the ability to read and understand any one of the languages, namely English, Malay, Tamil and Mandarin, and also able to answer the questionnaire independently.

\subsection{Participants}

Study population consisted of young children aged 5-7 and 8 -12 years as well as adolescent aged 13- 18 years. These children and adolescent were recruited from the continently selected primary and secondary schools located in Klang valley area. All participants were given information sheets and signed parental consent forms were obtained prior to the administration of the questionnaire.

\subsection{Methods}

After parental consents were obtained, the participants were then given a standardized questionnaire to be completed independently. It took approximately 15 minutes for participants to complete the questionnaire. Besides, parents of the participants were also asked to complete a standardized questionnaire, this process took approximately 15 minutes to complete.

The test-retest reliabilily was assessed by re-approaching the same group of participants and parents with an identical copy of the questionnaire after a 2-week period. The time interval was determined to avoid any possibility of recall in answering the questionnaire among the participants previously.

\subsection{Statistical Analysis}

In terms of reliability, the Cronbach's alpha value was used to demonstrate the internal reliability. By convention, a Cronbach's alpha value of at least 0.70 is highly desirable (Anonymous, 2002; Cronbach, 1951). Predictive validity studies how one measure of behavior relates to another, this is normally being quantified by correlation coefficient (Elmes, Kantowitz, \& Roediger, 2006). Therefore, the predictive strength of the parent proxy report on the child self report was quantified using the correlation coefficient.

The analyses were performed using STATA software version 11.0, and statistical significance was set at $5 \%$. All 
missing data were excluded from analyses.

\section{Results}

\subsection{Response Rate}

Since all participants completed the questionnaires at the first and second visits held 2-week apart, a response rate of $100 \%$ was reported for this study.

\subsection{Demographic Data}

Table 1. Sample Characteristics from Child Self Report

\section{Children aged 5-7 years}

\begin{tabular}{|c|c|c|c|c|}
\hline & Malay $(\mathrm{N}=159)$ & English $(\mathrm{N}=156)$ & Mandarin $(\mathrm{N}=151)$ & Tamil $(\mathrm{N}=151)$ \\
\hline \multicolumn{5}{|l|}{ Age (years) } \\
\hline Mean (SD) & $7(0.4)$ & $7(0.1)$ & $6(0.5)$ & $7(0.6)$ \\
\hline Female, n (\%) & $100(63)$ & $118(76)$ & $75(50)$ & $73(48)$ \\
\hline \multicolumn{5}{|c|}{ Children aged 8-12 years } \\
\hline & Malay $(\mathrm{N}=150)$ & English $(\mathrm{N}=168)$ & Mandarin $(\mathrm{N}=151)$ & Tamil $(\mathrm{N}=159)$ \\
\hline \multicolumn{5}{|l|}{ Age (years) } \\
\hline Mean (SD) & $9(1.1)$ & $10(0.8)$ & $9(1.3)$ & $10(0.9)$ \\
\hline Female, n (\%) & $77(51)$ & $107(64)$ & $63(42)$ & $92(58)$ \\
\hline \multicolumn{5}{|c|}{ Adolescent aged 13-18 years } \\
\hline & Malay $(\mathrm{N}=150)$ & English $(\mathrm{N}=150)$ & Mandarin $(\mathrm{N}=148)$ & Tamil $(\mathrm{N}=158)$ \\
\hline \multicolumn{5}{|l|}{ Age (years) } \\
\hline Mean (SD) & $14(0.9)$ & $14(1.4)$ & $16(1.2)$ & $14(1.0)$ \\
\hline Female, n (\%) & $78(52)$ & $120(80)$ & $69(47)$ & $96(61)$ \\
\hline
\end{tabular}

The demographic background of the children and adolescent were summarized in Table 1. Majority of the participants from all languages were female, except for children aged 5-7 years in Tamil version of PedsQL (48\%), children 8-12 years in Mandarin version of PedsQL (42\%) and adolescent aged 13-18 years in Mandarin version of PedsQL (47\%). The average age of the participants was about the same in all versions of PedsQL. In comparison with other versions of PedsQL, the average age for Chinese children was lower in both the age groups of 5-7 years as well as 8-12 years, but the average age for Chinese adolescent was the highest.

Table 2. Sample Characteristics from Parent Proxy Report

\begin{tabular}{|c|c|c|c|c|}
\hline \multicolumn{5}{|c|}{ Parent of Children aged 5-7 years } \\
\hline & Malay $(\mathrm{N}=153)$ & English $(\mathrm{N}=156)$ & Mandarin $(\mathrm{N}=0)$ & Tamil $(\mathrm{N}=137)$ \\
\hline \multicolumn{5}{|l|}{ Age (years) } \\
\hline Mean (SD) & $39(7.3)$ & $39(6.6)$ & & $39(6.7)$ \\
\hline Female, n (\%) & $65(41)$ & $84(54)$ & & 59 (39) \\
\hline Government & $23(15)$ & $22(14)$ & & $17(11)$ \\
\hline \multicolumn{5}{|l|}{ Employee, n (\%) } \\
\hline $\begin{array}{ll}\text { Tertiary } & \text { Academic }\end{array}$ & $37(23)$ & $82(53)$ & & $27(18)$ \\
\hline \multicolumn{5}{|l|}{ Qualification, n (\%) } \\
\hline \multicolumn{5}{|c|}{$\overline{\text { Parent of Children aged 8-12 years }}$} \\
\hline & Malay $(\mathrm{N}=140)$ & English $(\mathrm{N}=151)$ & Mandarin $(\mathrm{N}=0)$ & Tamil $(\mathrm{N}=159)$ \\
\hline \multicolumn{5}{|l|}{ Age (years) } \\
\hline Mean (SD) & $41(6.4)$ & $42(6.6)$ & & $43(5.9)$ \\
\hline Female, n (\%) & $75(50)$ & $74(44)$ & 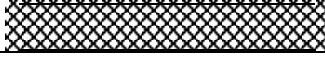 & $66(42)$ \\
\hline
\end{tabular}




\begin{tabular}{|c|c|c|c|c|}
\hline \multirow{2}{*}{$\begin{array}{l}\text { Government } \\
\text { Employee, n (\%) }\end{array}$} & $28(19)$ & $28(17)$ & \multirow{3}{*}{ 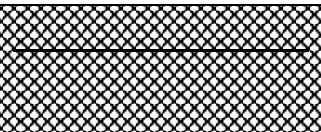 } & $40(25)$ \\
\hline & \multirow[b]{2}{*}{$51(34)$} & \multirow{3}{*}{$51(30)$} & & \multirow[b]{2}{*}{$32(20)$} \\
\hline \multirow{2}{*}{$\begin{array}{l}\text { Tertiary } \quad \text { Academic } \\
\text { Qualification, } \mathrm{n}(\%) \\
\end{array}$} & & & & \\
\hline & & & , & \\
\hline \multicolumn{5}{|c|}{ 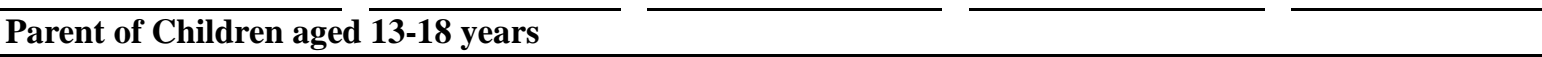 } \\
\hline & Malay $(\mathrm{N}=150)$ & English $(\mathrm{N}=150)$ & Mandarin $(\mathrm{N}=148)$ & Tamil $(\mathrm{N}=158)$ \\
\hline \multicolumn{5}{|l|}{ Age (years) } \\
\hline Mean (SD) & $45(6.6)$ & $44(6.2)$ & $45(5.8)$ & $43(5.8)$ \\
\hline Female, n (\%) & $43(29)$ & $67(45)$ & $78(53)$ & $67(42)$ \\
\hline \multirow{2}{*}{$\begin{array}{l}\text { Government } \\
\text { Employee, n (\%) }\end{array}$} & $12(8)$ & $17(11)$ & $4(3)$ & $20(13)$ \\
\hline & & & & \\
\hline Tertiary $\quad$ Academic & $5(3)$ & $38(25)$ & $14(9)$ & $12(8)$ \\
\hline Qualification, n (\%) & & & & \\
\hline
\end{tabular}

Demographic background was also collected for parents who participated in the parent proxy report; the results are summarized in Table 2. The responses from parents in Mandarin version were lower especially for age groups of 5-7 (23\%) and 8-12 (13\%) with incomplete demographic data compared to other versions of PedsQL. This was due to poor recruitment and lack of cooperation from parents. Majority of the parents were female for children aged 5-7 years in English PedsQL (54\%) with more than half possessed tertiary academic qualification (53\%); children aged 8-12 years in Malay PedsQL (50\%) with about one third possessed tertiary academic qualification (34\%); children aged 13-18 years in Mandarin PedsQL (53\%) with much lower percentage possessed tertiary academic qualification (9\%). Only a small percentage of parents, ranged from $3 \%$ to $25 \%$, reported working as government employee.

\subsection{Reliability of PedsQL}

Table 3. Cronbach’s Alpha Values and Child Self Report and Parent Proxy Report

\begin{tabular}{|c|c|c|c|c|c|c|}
\hline \multirow{2}{*}{$\begin{array}{l}\text { Age } \\
\text { Group }\end{array}$} & \multirow[t]{3}{*}{ Version of PedsQL } & \multirow{2}{*}{$\begin{array}{l}\text { Sample Size } \\
(\mathrm{N})\end{array}$} & \multicolumn{2}{|c|}{$\begin{array}{l}\text { Cronbach's Alpha } \\
\text { (child self report) }\end{array}$} & \multicolumn{2}{|c|}{$\begin{array}{l}\text { Cronbach’s Alpha (parent } \\
\text { proxy report) }\end{array}$} \\
\hline & & & Test & Retest & Test & Retest \\
\hline \multirow[b]{3}{*}{5.7} & & & Version & Version & Version & Version \\
\hline & Mandarin & 151 & 0.72 & 0.74 & & 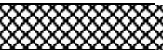 \\
\hline & Malay & 159 & 0.80 & 0.86 & 0.92 & 0.93 \\
\hline \multirow[b]{4}{*}{$8-12$} & English & 156 & 0.83 & 0.83 & 0.94 & 0.94 \\
\hline & Tamil & 151 & 0.88 & 0.92 & 0.87 & 0.91 \\
\hline & Mandarin & 151 & 0.78 & 0.85 & & \\
\hline & Malay & 150 & 0.90 & 0.92 & 0.91 & 0.95 \\
\hline \multirow{6}{*}{$13-17$} & English & 168 & 0.88 & 0.89 & 0.92 & 0.93 \\
\hline & Tamil & 159 & 0.85 & 0.89 & 0.82 & 0.88 \\
\hline & Mandarin & 148 & 0.86 & 0.88 & 0.86 & 0.90 \\
\hline & Malay & 150 & 0.90 & 0.89 & 0.92 & 0.88 \\
\hline & English & 150 & 0.89 & 0.91 & 0.92 & 0.92 \\
\hline & Tamil & 158 & 0.83 & 0.89 & 0.82 & 0.92 \\
\hline
\end{tabular}

As shown in Table 3, the Cronbach's alpha values for child self report in all versions of PedsQL were at least 0.70 , the value ranged from 0.72 to 0.90 in test versions of PedsQL, and the range of 0.74 to 0.92 was observed for the retest version of PedsQL. On the other hand, the values were at least 0.80 for the parent proxy report. The value ranged from 0.82 to 0.94 and 0.88 to 0.95 respectively for test and retest versions of PedsQL. These values clearly indicated the translated versions of PedsQL were reliable. 


\subsection{Validity of PedsQL}

Table 4. Correlation Values between Child Self Report and Parent Proxy Report

\begin{tabular}{|c|c|c|c|c|c|}
\hline \multirow{3}{*}{$\begin{array}{l}\text { Age } \\
\text { Group } \\
\end{array}$} & \multirow[b]{2}{*}{ Domains in PedsQL } & \multicolumn{4}{|c|}{ Versions of PedsQL } \\
\hline & & Mandarin & Malay & English & Tamil \\
\hline & & $\mathrm{N}=0$ & $N=157$ & $\mathrm{~N}=155$ & $\mathrm{~N}=146$ \\
\hline \multirow[t]{7}{*}{$5-7$} & Total Score & km & 0.40 & 0.38 & 0.32 \\
\hline & Physical Functioning & & 0.44 & 0.39 & 0.33 \\
\hline & Psychosocial Health Summary Score & & 0.32 & 0.39 & 0.33 \\
\hline & Emotional Functioning & & -0.38 & 0.34 & 0.32 \\
\hline & Social Functioning & 13 & 0.37 & 0.37 & -0.31 \\
\hline & School Functioning & 10 & 0.46 & 0.49 & 0.41 \\
\hline & & $\mathrm{N}=0$ & $\mathrm{~N}=150$ & $\mathrm{~N}=168$ & $\mathrm{~N}=158$ \\
\hline \multirow[t]{7}{*}{ 8-12 } & Total Score & m n m & 0.41 & 0.32 & 0.44 \\
\hline & Physical Functioning & & 0.39 & 0.32 & 0.28 \\
\hline & Psychosocial Health Summary Score & & 0.37 & 0.30 & 0.43 \\
\hline & Emotional Functioning & & 0.34 & 0.22 & 0.36 \\
\hline & Social Functioning & $\ldots$ & 0.22 & 0.21 & 0.38 \\
\hline & School Functioning & . & 0.47 & 0.24 & 0.28 \\
\hline & & $\mathrm{N}=138$ & $\mathrm{~N}=111$ & $\mathrm{~N}=133$ & $\mathrm{~N}=141$ \\
\hline \multirow[t]{6}{*}{$13-18$} & Total Score & 0.68 & 0.48 & 0.52 & 0.48 \\
\hline & Physical Functioning & 0.56 & 0.36 & 0.40 & 0.42 \\
\hline & Psychosocial Health Summary Score & 0.70 & 0.49 & 0.55 & 0.49 \\
\hline & Emotional Functioning & 0.62 & 0.52 & 0.50 & 0.38 \\
\hline & Social Functioning & 0.65 & 0.40 & 0.50 & 0.48 \\
\hline & School Functioning & 0.67 & 0.44 & 0.47 & 0.47 \\
\hline
\end{tabular}

Table 4 presented the correlation values between the child self report and parent proxy report, they were generally moderate for children in the age groups of 5-7 and 8-12 years, while the correlation values can be interpreted as moderate to high for children in the age group of 13-18 years old.

\section{Discussion}

The general findings from this study demonstrated that the translated versions of PedsQL possessed acceptable reliability and validity. By validating the PedsQL instrument in Malaysia, we hope to encourage more Health Related Quality of Life assessment in children healthcare. Besides, we hope these results can encourage the policymakers to incorporate the PedsQL instruments into future National Health Morbidity Survey conducted in Malaysia, to aid in identifying subgroups of children who are at risk for health problems. By doing so, further support in the development of strategic healthcare plans and school health clinics, identifying health disparities, promoting policies and legislation related to school health will aid the allocation of healthcare resources and improve children healthcare in Malaysia (Varni, Burwinkle, Seid, \& Skarr, 2003).

A high number of missing value raised the importance of situational circumstances at the time the survey was conducted. It was also noted that the pressure and the time limitation given to participants and parents to complete the questionnaire could potentially explain the incompleteness of the questionnaires.

The reported Cronbach's alpha values were at least 0.70 on the child self report and at least 0.80 on the parent proxy report. These values were consistent with the internal reliability reported in a study conducted in the United States of America (Varni, Seid, \& Kurtin, 2001).

The moderate to high correlations observed between the child self report and the parent proxy report supported the need to measure the perspective of child and parent in evaluating pediatric HRQOL. Although self report is considered as the standard in measuring perspective of HRQOL, it is equally important to study the perspective of child's HRQOL from parent as that could play a significant role in influencing the resource allocation and health initiative to optimize the well-being of children in family (Majnemer, Shevell, Rosenbaum, Law, \& Poulin, 2007).

Limitations existed in this study. The participants for this study were recruited only from the Klang valley area, which is an urban area, mainly due to restriction in logistics. Past study indicated the quality of life in urban area is significantly better than rural area (Verma, 2008). Therefore, it would be very interesting to study the quality of life of children and adolescent from urban area by using the identical copy of the translated PedsQL.

\section{Acknowledgements}

The authors expressed sincere thanks to the Director of General of the Ministry of Health Malaysia (MOH) for 
the permission to publish the research findings of this study. The authors were indebted to Dr James W. Varni and Ms Andrea Murison for their personal guidance. We would also like to thank MAPI Research Trust for granting us the permission to use the PedsQL instrument. This project was approved by the Medical Research Ethics Committee, MOH, and funded by a research grant (NMRR ID 08-1453-3048) from MOH.

\section{References}

Anonymous. (2002). Assessing health status and quality of life instruments: Attributes and review criteria. Qual Life Res, 11, 193-205. http://dx.doi.org/10.1023/A:1015291021312

Blazeby, J. M., Williams, M. H., Alderson, D., et al. (1995). Observer variation in assessment of quality of life in patients with oesophageal cancer. Br J Surg, 82, 1200-1203.

Cronbach, L. F. (1951). Coefficient alpha and the internal structure of tests. Psychometricka, 16, 297-334.

Department of Statistics Malaysia. (n.d.). National Product and Expenditure Accounts First Ouarter 2012. Retrieved August 15, 2012, from http://www.statistics.gov.my/portal/index.php?option= com_content\&view=article\&id=1587\%3A-national-product-and-expenditure-accounts-first-quarter-2012-u pdated-23052012\&catid=116\%3Aquarterly-gross-domestic-product\&Itemid=153\&lang=en .

Eiser, C., \& Morse, R. (2001). The measurement of quality of life in children: past and future perspectives. Journal of Developmental and Behavioral Pediatrics, 22, 248-246.

Elmes, D. G., Kantowitz, B. H., \& Roediger, H. L. III. (2006). Research methods in psychology. Belmont: Thomson Higher Education.

Koot, H. M., \& Wallander, J. L. (1999). Quality of life in child and adolescent illness, concept, methods and findings. Brunner-Routledge.

Spieth, L. E, \& Harris, C. V. (1996). Assessment of Health-Related Quality of Life in Children and Adolescents: An Integrative Review. Journal of Pediatric Psychology, 21(2), 175-193.

Majnemer, A., Shevell, M., Rosenbaum, P., Law, M., \& Poulin, C. (2007). Determinants of life quality in school-age children with cerebral palsy. Journal of Pediatrics, 151, 470-475.

Varni, J. W., Burwinkle, T. M., Seid, M., \& Skarr, D. (2003). The PedsQL 4.0 as a pediatric population health measure: Feasibility, reliability, and validity. Ambulatory Pediatrics, 3, 329-341.

Varni, J. W., Limbers, C., \& Burwinkle, T. M. (2007). Literature review: Health-related quality of life measurement in pediatric oncology: hearing the voices of the children. Journal of Pediatric Psychology, 32(9), 1151-1163.

Varni, J. W., Limbers, C. A., \& Burwinkle, T. M. (2007). How young can children reliably and validly self-report their health-related quality of life?: An analysis of 8,591 children across age subgroups with the PedsQLTM 4.0 Generic Core Scales. Health Qual Life Outcomes, 5(1). http://dx.doi.org/10.1186/1477-7525-5-1.

Varni, J. W., Seid, M., Knight, T. S., Uzark, K., \& Szer, I. S. (2002). The PedsQLTM 4.0 Generic Core Scales: Sensitivity, Responsiveness, and Impact on Clinical Decision-Making. Journal of Behavioral Medicine, 25(2), 175-193(19).

Varni, J. W., Seid, M., \& Kurtin, P. S. (2001). Life Inventory ${ }^{\mathrm{TM}}$ version 4.0 Generic Core Scales in Healthy and Patient Populations. Medical Care, 39(8), 800-812.

Varni, J. W., Seid, M., \& Rode, C. A. (1999). The PedsQL ${ }^{\mathrm{TM}}$ : measurement model for the pediatric quality of life inventory. Medical Care, 37, 126-139.

Varni, J. W., \& Setoguchi, Y. (1992). Screening for behavioral and emotional problems in children and adolescents with congenital or acquired limb deficiencies. Am J Dis Child, 146, 103-107.

Verma, S. K. (2008). Working and on-working rural and urban elderly: subjective well-being and quality of life. Indian Journal of Gerontology, 22(1), 107-118.

Walter, S. D., Eliasziw, M., \& Donner, A. (1998). Sample size and optimal designs for reliability studies. Statistics in Medicine, 17, 101-110.

\section{(cc) EY}

This work is licensed under a Creative Commons Attribution 3.0 License. 